\title{
Clinical Experiments of Orally Administering Therapy of Casein and Defatted Soya-Bean Hydrolysates
}

\author{
By \\ Shinichi Saito \\ (磂 藤 信一) \\ From the Medical Clinic of Prof. Kurokawa, Tohoku \\ University, Sendai
}

(Received for publication June 12, 1953)

We may easily suppose that various kinds of nutrients which have been decomposed into the form in which they are just going to be absorbed will permeate into the blood vessels through intestinal walls with no heavy burden. Co Tui $e t$ al. ${ }^{11}$ were the first who from this point of view employed amino acids, the final compost of protein, for patients as protein supplement of the body. Since then clinical utilization of hyperalimentation treatment with amino acids has been tried by many investigators, among whom was Nathan Steinberg ${ }^{2)}$ who used soya-bean hydrolysed with ferment for this purpose. Mostly used as animal amino acids is ferment-hydrolysed casein which componentally contains much of essential amino acids and as vegetable amino acids soya-beans. But the former is very expensive and when it is of thick density unpalatable. If such amino acids as fermenthydrolysed soya-bean, very cheap and not so unpalatable, are effectively used, it is most desirable. Examining vicissitude of symptoms, body weight, nitrogen balance, excretion rate of nitrogen in urine and other necessary items, I studied whether amino acids obtained by hydrolysing defatted soya-beans might be of service for the same purpose.

\section{EXPERIMENTAL}

During 2 years and 4 months of my experiment I treated 15 cases, but one case of them from the unsatisfactory collaboration on the part of the patient and one case from the selfishness of the patient could not produce reliable results. The other 13 reached significant conclusions.

\section{Methods}

The diet for the patients contained protein accurately calculated. It had a high calory within the limit possible. Furthermore, casein ferment-hydrolysate, defatted soya-bean ferment-bydrolysate and a mixture 
of the both were given, sometimes with maltose, sometimes not, to the patients. In this case 100 to $20 \mathrm{~g}$. of the mixture, which had been diluted in 500 to $200 \mathrm{cc}$. of water, was put on about two weeks for evacuation every day.

The analysis of the ingredients of the mixed amino acids by paper chromatography revealed casein amino acids to contain arginine, histidine, lysine, tryptophan, phenylalanine, tyrosine, methionine, cystine,leucine, isoleucine, valine, glycine, serine, proline, alanine, aspartic acid, glutamic acid, etc. and defatted soya-bean amino acids to contain the foregoing items except arginine, histidine, tryptophan, phenylalanine, besides asparagin. To examine nitrogen balance, the whole stool and urine the patient excreted were weighed every day.

The stool was homogenously stirred, part of which was taken out, dried, and reduced to powder in a mortar. Further, quantitative analysis of nitrogen was made of a part of the powdered stool, and then on the basis of the quantity of nitrogen thus obtained the quantity of nitrogen contained in the whole stool was calculated. The same process was carried on with urine. Quantitative analysis of nitrogen was made of part of homogenously churned urine, from the result of which was calculated the quantity of nitrogen contained in the whole urine. Kjehldhahl's method was followed. In the numerical calculation of nitrogen balance the accustomed method was pursued, that is, the calculation was made by subtracting the excreted nitrogen from that which had been given. Here trifle nitrogen containers, such as epidermis metabolite, nasal secrete, sweat, hair, etc. were excluded. To know the vicissitude of symptoms a card on which a number of main symptoms was written had been handed to each patient who could be made to put on it the four marks $(-)(+)$ $(H)(H)$ according to his conditions, so that a synthetic judgement, whether deterioration or improvement, might be brought.

When the three kinds of amino acids were given to patients, the dicision which had a better absorption rate of nitrogen was thus made. The nitrogen excreted in the urine of those patients whose nitrogen balance was kept positive was divided by the nitrogen given to them.

This is an excretion rate of nitrogen in urine, and when this rate was low the absorption was judged as good.

Further examination was conducted as to the variation of weight, change of nonprotein nitrogen remaining in the blood, quantity of serum protein and so on.

During about 17 days when amino acid solution was orally administered, several days before the treatment included, besides the diet given by me only such fruit as contained no or little calory and protein was allowed to give, Various vitamins were sufficiently supplemented through 


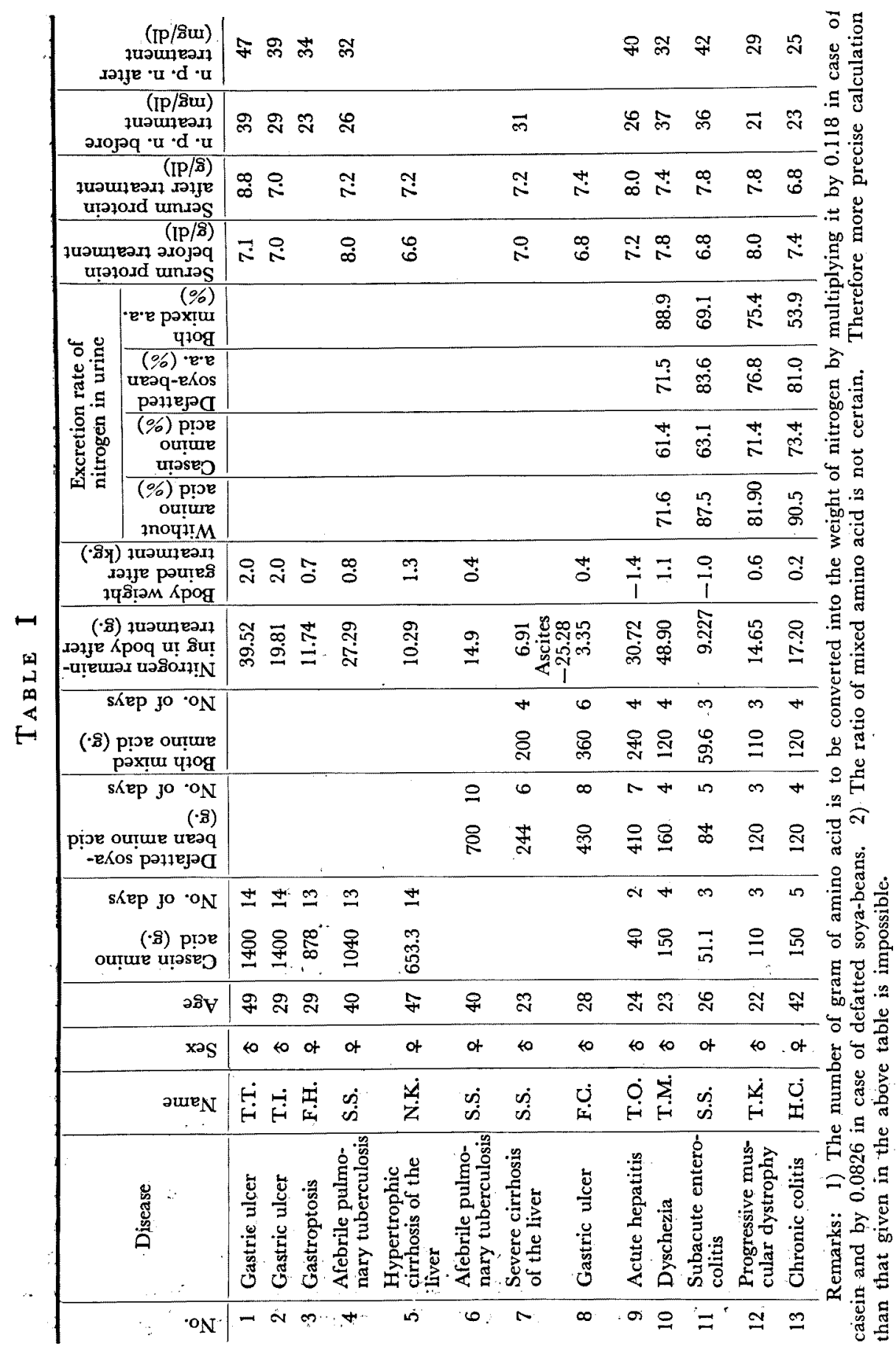


the skin. Subject, amount of amino acid administered, total number of nitrogen balance, absorption rate etc. were tabulated into Table I.

Results

When only casein hydrolysate was administered 4 cases out of 5 , from Case 1 to Case 5 in Table I, showed comparatively rapid increase in weight and bodily retention of nitrogen, excluding Case 3 of gastroptosis. Variation of physical strength was presumed by grip strength, and no case of decrease was found. Conditions of Case 5 of cirrhosis of the liver are shown in Table II below.

TABLE II

A Case of Cirrhosis of the Liver

\begin{tabular}{l|c|c|c|c|c|c|c}
\hline \multicolumn{1}{c|}{ Date } & $\begin{array}{c}\text { Casein } \\
\text { amino } \\
\text { acid (g.) }\end{array}$ & $\begin{array}{c}\text { Maltose } \\
\text { (g.) }\end{array}$ & $\begin{array}{c}\text { Calories } \\
\text { (Cal.) }\end{array}$ & $\begin{array}{c}\text { Nitrogen } \\
\text { given in } \\
\text { total (g.) }\end{array}$ & $\begin{array}{c}\text { Nitrogen } \\
\text { balance }\end{array}$ & $\begin{array}{c}\text { Grip } \\
\text { strength } \\
\text { (kg.) }\end{array}$ & $\begin{array}{c}\text { Body } \\
\text { weight } \\
\text { (kg.) }\end{array}$ \\
\hline 11/Aug. & 80.0 & 80.0 & 2966 & 20.64 & -0.172 & 16 & 63.2 \\
12 & 80.0 & 80.0 & 2966 & 20.64 & -0.446 & 15 & 63.2 \\
13 & 26.66 & 26.66 & 2555 & 12.74 & -1.501 & 16 & 63.3 \\
14 & 26.66 & 26.66 & 2555 & 12.74 & -2.644 & 16 & 63.3 \\
15 & 30.00 & 30.00 & 2581 & 14.74 & -0.670 & 10 & 63.3 \\
16 & 30.00 & 30.00 & 2581 & 14.74 & +0.266 & 12 & 63.3 \\
17 & 40.0 & 40.00 & 2658 & 15.92 & -0.931 & 10 & 64.0 \\
18 & 40.0 & 40.0 & 2658 & 15.92 & +1.335 & 15 & 64.0 \\
19 & 50.0 & 50.0 & 2735 & 17.10 & -0.239 & 14 & 64.3 \\
20 & 50.0 & 50.0 & 2735 & 17.10 & +2.820 & 12 & 64.0 \\
21 & 50.0 & 50.0 & 2735 & 17.10 & +1.654 & 14 & 64.9 \\
22 & 50.0 & 50.0 & 2735 & 17.10 & +3.148 & 16 & 64.1 \\
23 & 50.0 & 50.0 & 2735 & 17.10 & +2.822 & 12 & 64.2 \\
24 & 50.0 & 50.0 & 2735 & 17.10 & +4.931 & 14 & 64.4 \\
& & & & & & &
\end{tabular}

Remarks: 1) N. given in 14 days; $230.68 \mathrm{~g}$. 2) N. excreted in urine; $176.94 \mathrm{~g}$. 3) N. excreted in stool; $43.37 \mathrm{~g}$. 4) Total N. balance +10.37. 5) Increased body weight; ca $1.2 \mathrm{~kg}$.

Administration of only defatted soya-bean hydrolysate served little for weight increase, though positive nitrogen balance was maintained.

In the 4 cases where the three kinds of amino acid were administered to each patient, bodily absorption rate of nitrogen was lowest in the case administered with defatted soya-bean hydrolysate if the rate is inversely proportional to the excretion rate of nitrogen in urine. One of the cases is given as Table III. Now I shall state about changes of symptoms. In the two cases of gastric ulcer for which casein hydrolysate was employed niches required almost as many days to disappear as in case of spontaneous 
TABLE III

A Case of Progressive Muscular Dystrophy

\begin{tabular}{l|c|c|c|c|c|c|c}
\hline Date & $\begin{array}{c}\text { Casein } \\
\text { amino } \\
\text { acid } \\
(\mathrm{g} .)\end{array}$ & $\begin{array}{c}\text { Defatted } \\
\text { soya-bean } \\
\text { amino } \\
\text { acid (g.) }\end{array}$ & $\begin{array}{c}\text { Calories } \\
\text { (Cal.) }\end{array}$ & $\begin{array}{c}\text { Nitrogen } \\
\text { given } \\
(\mathrm{g} .)\end{array}$ & $\begin{array}{c}\text { Nitrogen } \\
\text { balance }\end{array}$ & $\begin{array}{c}\text { Grip } \\
\text { strength } \\
(\mathbf{k g} .)\end{array}$ & $\begin{array}{c}\text { Body } \\
\text { weight } \\
(\mathrm{kg} .)\end{array}$ \\
\hline $19 /$ Sept. & 0 & 0 & 2113 & 12.5 & -1.305 & 50 & 49.9 \\
20 & 0 & 0 & 2113 & 12.5 & +2.220 & 50 & 49.5 \\
21 & 0 & 0 & 2113 & 12.5 & -1.947 & 50 & 49.5 \\
22 & 20 & 0 & 2167 & 14.86 & +1.326 & 50 & 49.4 \\
23 & 30 & 0 & 2195 & 16.04 & +1.804 & 51 & 49.0 \\
24 & 30 & 0 & 2195 & 16.04 & +1.184 & 51 & 49.2 \\
25 & 30 & 0 & 2195 & 16.04 & +1.137 & 50 & 49.2 \\
26 & 10 & 10 & 2146 & 14.50 & -1.348 & 50 & 49.9 \\
27 & 15 & 15 & 2169 & 15.50 & +2.383 & 50 & 49.6 \\
28 & 15 & 15 & 2169 & 15.50 & +1.517 & 51 & 49.6 \\
29 & 15 & 15 & 2169 & 15.50 & +3.604 & 50 & 50.1 \\
30 & 0 & 30 & 2170 & 14.97 & +0.289 & 50 & 50.2 \\
$1 /$ Oct. & 0 & 30 & 2170 & 14.97 & +0.837 & 50 & 50.1 \\
2 & 0 & 30 & 2170 & 14.97 & +0.849 & 50 & 50.2 \\
3 & 0 & 30 & 2170 & 14.97 & +1.105 & 52 & 50.2 \\
& & & & & &
\end{tabular}

Remarks :

1) Average excretion rate of $\mathrm{N}$ in urine:

a) from $19 /$ Sept. to $21 /$ Sept. $81.90 \%$

b) from $22 /$ Sept. to $25 /$ Sept. $71.43 \%$

2) a) N. given in 15 days $22.42 \mathrm{~g}$.

c) from $26 /$ Sept. to $29 /$ Sept. $75.41 \%$

b) N. excreted in urine $164.63 \mathrm{~g}$.

c) N. excreted in stool $39.13 \mathrm{~g}$.

d) from $30 /$ Sept. to $3 /$ Oct. $76.81 \%$

d) Total N. balance +17.66

e) Body weight increased in 15 days by $0.6 \mathrm{~kg}$.

cure. Of gastroptosis I had one case where the condition was thought to have become reactive to strychinine preparations. In the case of cirrhosis of the liver edema in the skin went down remarkably, besides the body weight increased without ascites. No particular effect was observed on pulmonary tuberculosis.

Generally speaking, at the beginning of this treatment unpalatability of casein amino acid caused the loss of appetite for average three days, but it recovered on the fourth day.

With defatted soya-bean hydrolysate I could not see any apparently improved case, though it has an advantage of not unpalatability. Mixed amino acid solution came next to casein amino acid in effectiveness.

In the use of defatted soya-bean amino acids an unexpected effect was achieved on a case of dyschezia. These amino acids were so efficacious as a laxative that a patient who had defecated once in ten days came to 
evacuate soft stool once every day, maintaining positive nitrogen balance. Needless to say, casein amino acids are of better service as an aperient medicine.

In the case of chronic colitis on which constipation has ill effects, the unwellness felt in the part of hypogastrium was diminished by using amino acid.

Nonprotein nitrogen in the blood of the patients who were under the treatment with amino acid increased in 8 cases out of 9 , and serum protein increased in quantity in 6 cases out of 11 ; one unchanged and 4 decreased.

Sufferers from gastric ulcer with hyperacidity were given $500 \mathrm{cc}$. of casein amino acid solution (pH 5.6) a day, $100 \mathrm{cc}$. for one time, and gastric juice was examined after 30 minutes. In one case was hyperacid and the other normoacid.

\section{Comment}

We have two ways of decomposing protein artificially-decomposition with acid and decomposition with ferment.

If amino acid is produced by decomposing protein with acid the salt which is also produced then makes the amino acid very difficult to take out in its pure form. Moreover, this salt irritates the wall of the stomach, or urges the secretion of gastric juice, sometimes causing catarrh. Therefore the amino acid to be used for medical treatment must be the one decomposed with ferment. For this reason I made my experiment with this sort of amino acids, and recognized the following points.

In the oral administration of amino acids the difference of materials influences utilization. Absorption rate through intestinal canals is thought much higher in the form of amino acid than in that of source material. The density of amino acid solution seems best when it makes the stool of its users slightly soft. Taking too much of it is apt to be a cause of diarrhea.

To sufferers from hepatitis for which effects of methionine can be expected, even defatted soya-bean amino acids may bring satisfactory results, if they can take it from their mouth.

The vigor of patients does not always increase parallel with the increase of body weight, but nitrogen balance must always be positive. Increases of body weight seem to be influenced by the amount of such amino acids as lysine, tryptophan, histidine, etc. which bear a close relation to the increased weight, as well as by the maintenance of positive nitrogn balance. Furthermore, difference between casein amino acids and defatted soya-bean amino acids in nitrogen supplement is related to the nitrogen content in the same weight. The nitrogen content ratio of casein 
amino acids I used to defatted soya-bean amino acids is 1:0.7.

From a half to a third of the protein supplied to the patients was given in the form of amino acid. I think it is best that the whole amount of protein to be supplied should always be about $90 \mathrm{~g}$.

Donald ${ }^{3)}$ is of opinion that amino acid administering therapy is not so beneficial, but, though defatted soya-bean amino acids maintain only positive nitrogen balance and vigor, casein amino acids make up the protein of body well and are very advantageous to those patients who can not take solid food enough.

When amino acid solution was given, with maltose mixed, the effect against fermentation in intestine was not so beneficial as had been expected. Rather it would be fruitful if efforts be made to prevent saprophytes from multiplying in the amino acid to be administered.

The cause of diarrhea seems to be attributed, in most part, to the multiplication, fermentation, putrefaction of bacilli. This has been published by Co Tui et al.41

For calory to be increased addition of maltose has a significance.

In case there is some derangement in absorption like enterocolitis, of course, good results cannot be expected.

The increase rate of weight of sufferers from gastric ulcer is very high, but the increase is not parallel with the disappearance of niches.

Administration through the mouth, though unpalatable, allows a great quantity of the acid compared with that through the skin. Collateral effects are not so marked. ${ }^{5-6}$ )

\section{Conclusion}

I gave to patients of various diseases casein amino acids, defatted soay-bean amino acids and a mixture of the both through their mouth and studied on the fortune of nitrogen, the change of symptoms and other items.

Followings are the conclusions I arrived at.

1. Compared with defatted soya-bean amino acids, casein amino acids are a much more excellent source of nitrogen.

2. Casein amino acids are not only remarkably efficacious to cirrhosis of the liver, but also exercise good influences on other diseases by increasing vigor and weight.

3. Neither casein amino acids nor defatted soya-bean amino acids aggravate the conditions of the patients.

\section{References} 120, 99 .

1) Co Tui, Wright, Mulholland, Carabba, Barcham \& Vinci, Ann. Surg., 1944, 
2) Steinberg, Rev. Gastroent., 1948, 15, 319.

3) Donald, Edinburgh Med. J., 1951, 58, 52.

4) Co Tui et al., Gastroenterology, 1945, 5, 5.

5) Kurota, Kurauchi \& Muramatsu, Osaka Ikadaigaku Z, (J. of Osaka Med. Col.,) 1952, 12, 124.

6) Fuse \& Oji, Nippon Rinsho (Jap.), 1949, 7, 23. 